doi: 10.2306/scienceasia1513-1874.2013.39.214

\title{
Morphology, viability, and germinability of pollen from two forms of Nymphaea nouchali var. versicolor, a day-blooming waterlily
}

\author{
Kitti Bodhipadma $^{\mathrm{a}}$, Sompoch Noichinda ${ }^{\mathrm{a}}$, Panit Thaiyanto ${ }^{\mathrm{a}}$, David W.M. Leung ${ }^{\mathrm{b}, *}$ \\ a Department of Agro-Industrial Technology, Faculty of Applied Science, \\ King Mongkut's University of Technology North Bangkok, Bangsue, Bangkok 10800 Thailand \\ b School of Biological Sciences, University of Canterbury, Private Bag 4800, Christchurch 8140, New Zealand \\ *Corresponding author, e-mail: david.leung@canterbury.ac.nz \\ Received 14 Aug 2012 \\ Accepted 9 Jan 2013
}

\begin{abstract}
Pollen morphology, viability, and germinability of two distinct forms (Bua Phan and Bua Phuean) of Nymphaea nouchali var. versicolor, one of the only two naturally occurring native varieties of the day-blooming waterlily in Thailand, were studied. Under a scanning electron microscope, the pollen morphology of the two forms of N. nouchali was very similar. The pollen grains were nearly ellipsoidal, heteropolar, round-shaped from one side and boat-shaped from the other side, and had a smooth surface and a ring-like aperture around the equator. There was no significant difference between the pollen viability (95\%) of the Bua Phan and Bua Phuean forms examined after acetocarmine staining. Pollen germinability was evaluated on a medium supplemented with various concentrations of sucrose under different incubation temperatures and illumination conditions. The highest percentages of pollen germination in the Bua Phan (93\%) and Bua Phuean (80\%) forms took place at $32{ }^{\circ} \mathrm{C}$ in the dark on a medium supplemented with $5 \%$ sucrose. These germination results were significantly different. The dissimilar germination response is also consistent with the current classification of the versicolor variety into two forms.
\end{abstract}

KEYWORDS: aquatic plants, in vitro pollen germination, pollen fertility, scanning electron microscopy

\section{INTRODUCTION}

Nymphaea is the largest and most geographically diverse genus in the family Nymphaeaceae. There are about 50 waterlily species in the genus which are found in all continents except Antarctica ${ }^{1}$. N. nouchali Burm. f. (Synonyms: N. stellata Wild) is the only day-blooming waterlily native to Thailand ${ }^{2,3}$. It is an emergent aquatic macrophyte which is also commonly known as a blue waterlily ${ }^{4}$. It has long been used in the Ayurveda and Siddha systems of medicine ${ }^{5}$. Thus far, floral extracts from this plant have diverse pharmaceutical applications including hepatoprotective, antihyperglycaemic, antihyperlipidaemic, and antidiabetic activities to cure many diseases and disorders ${ }^{6-9}$.

There are only two naturally occurring varieties of the day-blooming waterlily species in Thailand, namely cyanea and versicolor. The flower of cyanea has mauve colour which fades after the first day of blooming. For versicolor, there are two distinct forms which have been classified as Bua Phan and Bua Phuean. Generally, Bua Phan has bigger flowers than Bua Phuean. The flower of Bua Phan has pale bluish purple petals which typically change its colour to pink after the second day of blooming whereas that of Bua Phuean comprises white petals with pale bluish purple tips and does not change colour after blooming ${ }^{3}$.

Pollen development and morphology of Nymphaea have been studied or compared in many species such as $N$. alba, N. candida, N. mexicana, $N$. odorata, and N. tetragona ${ }^{10-12}$. However, there is a paucity of assessment on pollen viability and germinability of this genus. Besides the overt differences in the flower size and petal colour, little is known about other aspects of the floral biology of the two forms of $N$. nouchali variety versicolor. Therefore, the objective of this study was to examine and compare the morphology of Bua Phan and Bua Phuean pollen using both light and scanning electron microscopy. In addition, the viability of the pollen and their germination under in vitro conditions were determined to assess the pollen fertility potential.

\section{MATERIALS AND METHODS}

On the second day of blooming, flowers of the Thai native $N$. nouchali var. versicolor (forms Bua Phan 
and Bua Phuean) were taken at around 8 a.m. (the time at which the flowers just started opening) from a natural pond in Pathum Thani province, Thailand. The dehiscent anthers of both forms were taken from six different flowers at anthesis were gathered and shaken to release the pollen onto a Petri dish $(80 \mathrm{~mm}$ diameter). Then, the pollen grains were brushed over the surface of a pollen germination medium modified after Mercado et $\mathrm{al}^{13}$ consisting of $0.1 \mathrm{mM}$ boric acid and $1 \mathrm{mM} \mathrm{CaCl} 2$ in combination with various concentrations of sucrose $(5,10$, and $20 \% \mathrm{w} / \mathrm{v})$. This medium had previously been adjusted to $\mathrm{pH} 5.7$, gelled with $0.9 \%(\mathrm{w} / \mathrm{v})$ agar and autoclaved at $121^{\circ} \mathrm{C}$ and 15 psi for $20 \mathrm{~min}$ before it was poured into Petri dishes (80 $\mathrm{mm}$ diameter). After placing pollen grains on these three media types, the treatments were kept under four different incubation combinations $(22 \pm 2$ or $32 \pm 2{ }^{\circ} \mathrm{C}$ and under light at $5.87 \mu \mathrm{mol} \mathrm{m} \mathrm{m}^{-2} \mathrm{~s}^{-1}$ or in the dark). Germination of pollen was examined under a light microscope (ML2000, Meiji Techno Co., Ltd.) over a period of $24 \mathrm{~h}$. There were 5 replicate Petri dishes per treatment with pollen sown on the germination medium. At least 3 fields in each Petri dish were investigated to count pollen grains with or without pollen tubes. Photos of germinating pollen grains were taken using a digital camera (Olympus C-760, Olympus Corporation, Japan).

Size and viability of the pollen from the two forms of Thai native waterlily were also observed after staining the pollen grains with $1 \%(\mathrm{w} / \mathrm{v})$ acetocarmine ${ }^{14}$. A pollen grain that had abnormal shape or lack of the stain was considered to be non-viable. Samples of the pollen were sent immediately following collection without any chemical treatment to the Scientific and Technological Research Equipment Centre, Chulalongkorn University for scanning electron microscope (SEM) analysis.

For statistical analysis, pollen sizes, and percentages of pollen viability and germination were first subjected to Analysis of Variance. If significant, Tukey's range test (HSD) comparison of means was performed at the significance level of $P<0.05$ by using SPSS for Windows version 15.0 (SPSS Inc., 2006).

\section{RESULTS AND DISCUSSION}

N. nouchali var. versicolor Bua Phan and Bua Phuean are aquatic perennial herbs. These indigenous dayblooming waterlilies of Thailand can be found in swamps, marshes, and rice fields in many regions of the country. Even though Bua Phan and Bua Phuean are placed in the same variety, it is clear that their flowers are of dissimilar size even to our naked eyes

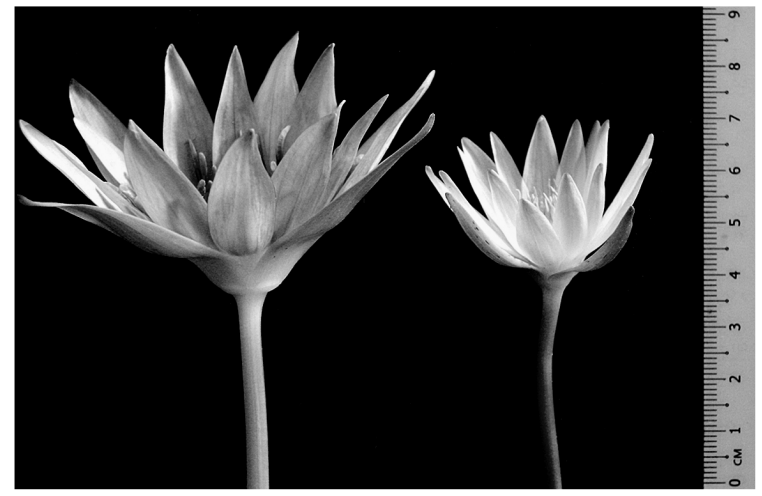

Fig. 1 Flowers of N. nouchali var. versicolor Bua Phan (left) and Bua Phuean (right).

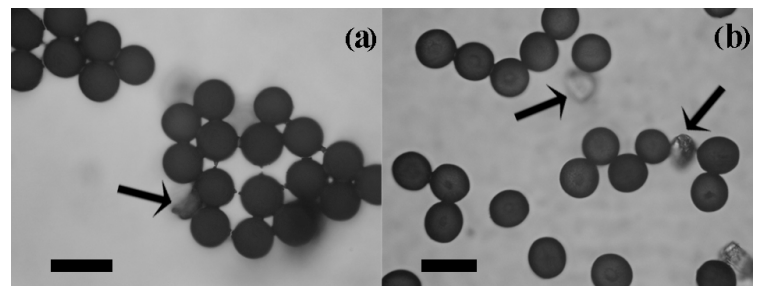

Fig. 2 Pollen of $N$. nouchali var. versicolor (a) Bua Phan and (b) Bua Phuean after staining (scale bar $=50 \mu \mathrm{m}$, arrow = non-viable pollen).

(Fig. 1). Staining with $1 \%$ acetocarmine suggested that a majority (around 95\%) of their pollen grains were viable and there was no significant difference in the viability of pollen between these two forms (Fig. 2). The high pollen viability measured by acetocarmine staining in $N$. nouchali is consistent with high viability found for $N$. odorata, based on pollen germination in vivo ${ }^{12}$.

The shape of viable pollen from both forms under a light microscope was nearly spheroidal (Fig. 2) and there was no significant difference in the size of the pollen of the two forms of the day-blooming waterlily. Perhaps it is not surprising that there is no correlation between size of the flowers and shape of pollen from both forms of the waterlily as they are classified as the same species. SEM micrographs of the pollen of these two forms showed that both had the same external morphology (Fig. 3a, b). The pollen grains were nearly ellipsoidal, heteropolar, round from one view and boat-shaped from another view, and had a ring-like sulcus around the equator namely zonasulculus ${ }^{15}$. The exine sculpture on both proximal and distal surfaces (polarity was judged based on similarity to other Nymphaea spp. ${ }^{10}$ ) of the pollen grains was of psilate ornamentation (Fig. 3c-f). Determination and 


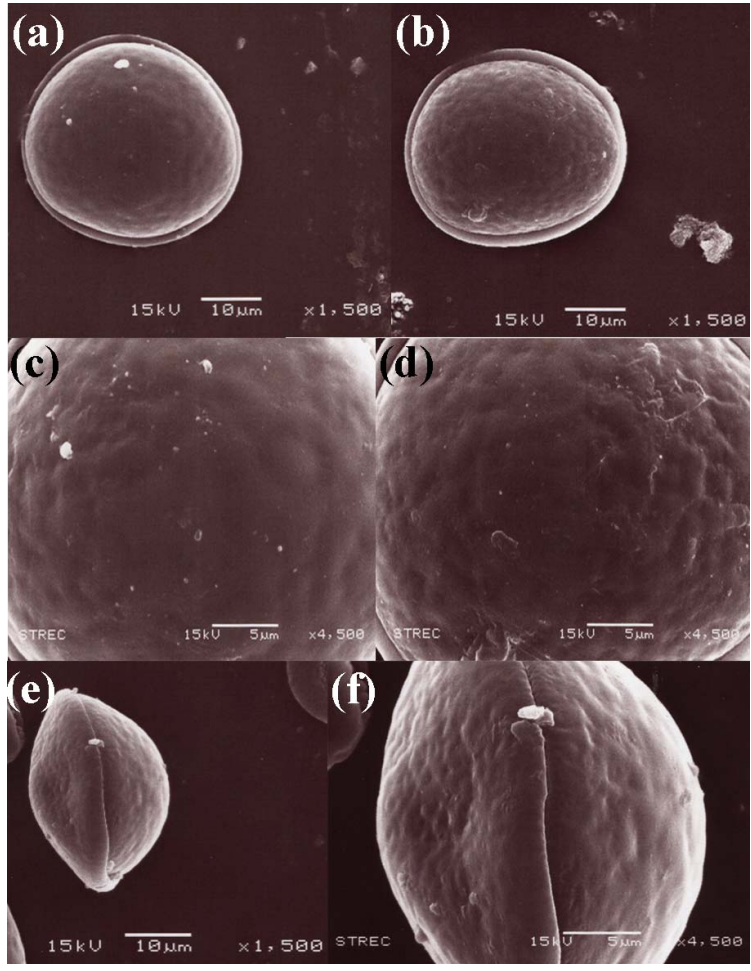

Fig. 3 SEM observations on pollen morphology of N. nouchali var. versicolor (a) Bua Phan and (b) Bua Phuean. Pollen surface on distal pole at polar view of (c) Bua Phan and (d) Bua Phuean. Distal and proximal surfaces of Bua Phan pollen at equatorial view, (e) whole pollen and (f) close-up view.

comparison via SEM on pollen morphology among species and cultivars is an excellent tool to expand the knowledge of reproductive biology ${ }^{16}$. Had there been no SEM observations, we would have accepted that the pollen of the two forms of waterlily studied here was spherical and centrosymmetrical as observed under a light microscope when the pollen grains were hydrated. It is clear that when viewing pollen under a microscope, it is important to bear in mind the hydration status of the pollen.

In contrast to the results for $N$. nouchali, the pollen grains of $N$. mexicana had a psilate distal surface, a verrucate proximal surface, and were anazonasulculus ${ }^{10}$. Volkova and Shipunov also found morphological variation of pollen among some Nymphaea species ${ }^{11}$. The exine sculpture of the proximal surface on the pollen of $N$. tetragona was dissimilar to that of $N$. alba and $N$. candida. Compared with the observations in this study, the shape of the pollen of these 3 species was noticeably different from the versicolor variety of $N$. nouchali. Taken together,

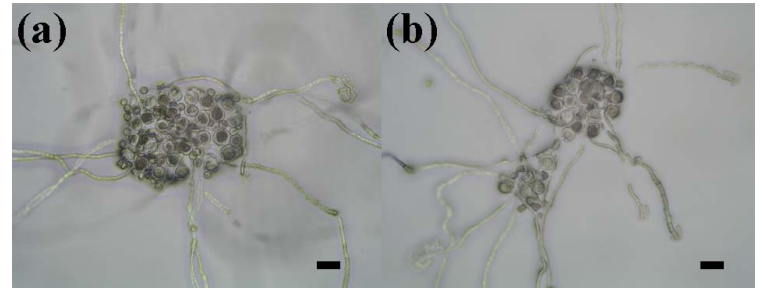

Fig. 4 Pollen germination of N. nouchali var. versicolor (a) Bua Phan and (b) Bua Phuean on medium supplemented with $5 \%$ sucrose at $32{ }^{\circ} \mathrm{C}$ in the dark (scale bar $=100 \mu \mathrm{m}$ ).

these findings indicated that the pollen of different Nymphaea species has divergent morphologies while those of the two different forms of $N$. nouchali variety versicolor were not different.

For in vitro pollen germination of Bua Phan and Bua Phuean, the effects of three factors namely sucrose concentration, temperature, and light conditions were found to be important. In many previous studies, optimization of one or two of these factors were sufficient to achieve high pollen germination rates ${ }^{17,18}$. After they had been sown for $2 \mathrm{~h}$ on pollen germination medium, swelling of pollen was observed in both forms of the day-blooming waterlily. However, different treatments resulted in various pollen germination percentages. Under light, less than $10 \%$ pollen germinated irrespective of the sucrose concentration or germination temperature used. In contrast, the highest germination percentages for Bua Phan and Bua Phuean were observed (Figs. 4 and 5) under the condition of $5 \%$ sucrose, $32{ }^{\circ} \mathrm{C}$ in the dark. They were $93.5 \pm 0.6$ and $80 \pm 1 \%$, respectively, and were significantly different. The reason(s) for the remarkably better pollen-germination efficiency of these two forms of the day-blooming waterlily in the dark than under light is obscure. Nevertheless, the physiological significance of the in vitro germination data remains to be established.

Under the optimized environmental conditions (in the dark at $32^{\circ} \mathrm{C}$ ), sucrose concentration played a crucial role on the in vitro germination of Bua Phan and Bua Phuean pollen. Sucrose concentrations higher than 5\% led to fewer pollen germinated. Interestingly, the sucrose concentration in the stigmatic fluids of open flowers of Nymphaea spp. is likely to be lower than 5\% and therefore would not pose a problem for pollen germination under natural conditions ${ }^{19}$. The pollen germination result obtained in the present study was obviously in contrast to that of other studies showing that $5-20 \%$ sucrose enhanced in vitro pollen germination ${ }^{20}$. 


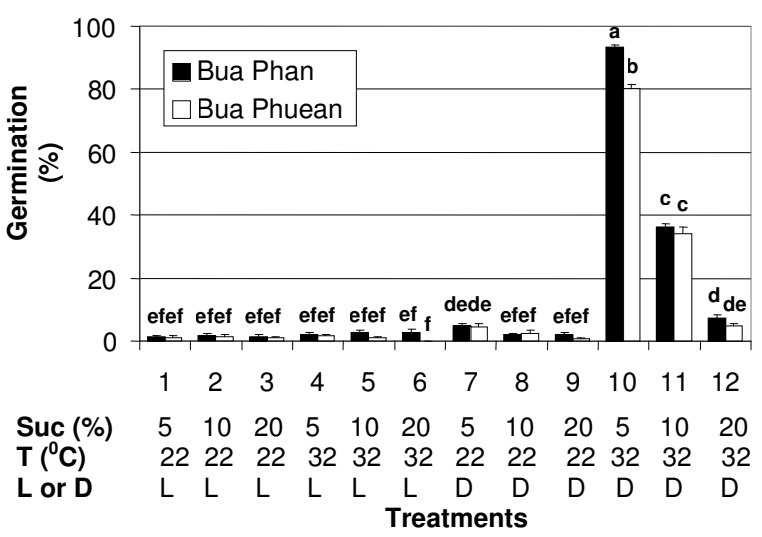

Fig. 5 Pollen germination of $N$. nouchali var. versicolor Bua Phan and Bua Phuean in different treatments (Suc: sucrose; $\mathrm{T}$ : temperature $\pm 2{ }^{\circ} \mathrm{C}$; L: light, D: dark). Values are means of 15 replications $\pm \mathrm{SE}$ and those marked by same letter are not significantly different (ANOVA, $P<0.05$ ).

Temperature is known to affect pollen germination. In pigeon pea, the most favourable temperature for pollen germination of cv. H-77-216 was $22^{\circ} \mathrm{C}$ while it was $27^{\circ} \mathrm{C}$ for cv. ICPL- $151^{21}$. On the contrary, the highest rate of in vitro pollen germination $(65 \%)$ was found at $20^{\circ} \mathrm{C}$ in eight genotypes of apri$\cot ^{15}$. In the present experiment, a high temperature $\left(32^{\circ} \mathrm{C}\right)$ favoured in vitro germination of both Bua Phan and Bua Phuean pollen. This might be related to the fact that they are day-blooming waterlilies. Nevertheless, the two forms of the versicolor variety had significantly different percentages of pollen germination at the same temperature.

In conclusion, the dissimilar physiological response regarding in vitro pollen germination was in addition to the overt difference in flower size and petal colour between Bua Phan and Bua Phuean. This is also consistent with the current practice of treating Bua Phan and Bua Phuean as two dissimilar forms of the versicolor variety of the day-blooming waterlily.

\section{REFERENCES}

1. Löhne $\mathrm{C}$, Borsch $\mathrm{T}$, Jacobs SWL, Hellquist CB, Wiersema JH (2008) Nuclear and plastid DNA sequences reveal complex reticulate patterns in Australian water-lilies (Nymphaea subgenus Anecphya, Nymphaeaceae). Aust Syst Bot 21, 229-50.

2. Dezhi F, Wiersema JH (2001) Nymphaeaceae. Flora China 6, 115-8.

3. Chomchalow N, Chansilpa NN (2007) The role of the 'Suthasinobon' waterlily complex in introgressive hybridization. Assumption Univ J Tech 11, 67-76.

4. Hasan MR, Chakrabarti R (2009) Emergent aquatic macrophytes. In: Hasan MR, Chakrabarti R (eds)
Use of Algae and Aquatic Macrophytes as Feed in Small-Scale Aquaculture: A Review. FAO Fisheries and Aquaculture Technical Paper no. 531, FAO, Rome, pp 89-93.

5. Mohan Maruga Raja MK, Sethiya NK, Mishra SH (2010) A comprehensive review on Nymphaea stellata: a traditionally used bitter. $J$ Adv Pharmaceut Tech Res 1, 311-9.

6. Bhandarkar MR, Khan A (2004) Antihepatotoxic effect of Nymphaea stellata willd., against carbon tetrachloride-induced hepatic damage in albino rats. J Ethnopharmacol 91, 61-4.

7. Rajagopal K, Sasikala K (2008) Antidiabetic activity of hydro-ethanolic extracts of Nymphaea stellata flowers in normal and alloxan induced diabetic rats. Afr $J$ Pharm Pharmacol 2, 173-8.

8. Rajagopal K, Sasikala K (2008) Antihyperglycaemic and antihyperlipidaemic effects of Nymphaea Med $J$ in alloxan-induced diabetic rats. Singapore Med J 49, 137-41.

9. Rajagopal K, Sasikala K, Ragavan B (2008) Hypoglycemic and antihyperglycemic activity of Nymphaea stellata flowers in normal and alloxan diabetic rats. Pharmaceut Biol 46, 654-9.

10. Gabarayeva NI, El-Ghazaly G (1997) Sporoderm development in Nymphaea mexicana (Nymphaeaceae). Plant Systemat Evol 204, 1-19.

11. Volkova PA, Shipunov AB (2007) Morphological variation of Nymphaea (Nymphaeaceae) in European Russia. Nord J Bot 25, 329-38.

12. Williams JH, McNeilage RT, Lettre MT, Taylor ML (2010) Pollen tube growth and the pollen-tube pathway of Nymphaea odorata (Nymphaeaceae). Bot J Linn Soc 162, 581-93.

13. Mercado JA, Fernández-Muñoz R, Quesada MA (1994) In vitro germination of pepper pollen in liquid medium. Sci Hort 57, 273-81.

14. Girijashankar V (2010) Effect of Eucalyptus pollen isolation methods on pollen viability, debris content, quantity isolated and pollen density per stigma. J Plant Breed Crop Sci 2, 273-9.

15. Punt W, Hoen PP, Blackmore S, Nilsson S, Le Thomas A (2007) Glossary of pollen and spore terminology. Rev Palaeobot Palynol 143, 1-81.

16. Asma BM (2008) Determination of pollen viability, germination ratios and morphology of eight apricot genotypes. Afr J Biotechnol 7, 4269-73.

17. Končalová MN, Jičínská D, Sýkorová O (1976) Effect of calcium and sucrose concentration on pollen germination in vitro of six Rosa species. Biol Plantarum 18, 26-30.

18. Lyra DH, Sampaio LS, Pereira DA, Silva AP, Amaral CLF (2011) Pollen viability and germination in Jatropha ribifolia and Jatropha mollissima (Euphorbiaceae): Species with potential for biofuel production. Afr J Biotechnol 10, 368-74.

19. Thien LB, Bernhardt P, Devall MS, Chen Z, Luo Y, Fan 
J-H, Yuan L-C, Williams JH (2009) Pollination biology of basal angiosperms (ANITA grade). Am J Bot 96 , 166-82.

20. Bodhipadma K, Noichinda S, Yadbuntung I, Buaeiam W, Leung DWM (2010) Comparison of in vitro and in vivo inflorescence of common cockscomb (Celosia argentea var. cristata). Sci Asia 36, 68-71.

21. Singh I, Bharti S, Nandwal AS, Goswami CL, Varma SK (1992) Effect of temperature on in vitro pollen germination in pigeonpea. Biol Plantarum 34, 461-4. 